\title{
INTERIORIZAÇÃO DO TURISMO NA BAHIA \\ Uma tentativa de planejamento governamental
}

\author{
Guilherme Marback Neto*
}

\begin{abstract}
RF:SUMO: Identificação dos aspectos que conduziram o Governo da Bahia a plancjar o turismo no interior do Estado. Análise do tratralho executado pela Empresa responsável pela implantação de hotéis no interior.
\end{abstract}

UNITERMOS: Turismo: Bahia: planejamento governamental; interiorização de hotéis. Hotelaria: planejamento governamental; turismo no interior: Bahia.

ABSTRACT: Indentification of the aspects that conducted the government of Bahia to plan the tourism in the interior of the state. Critical analyses of the work executed from the organization responsable for the implement hotels in the intcrior.

KEY-WORDS: Tourism: Bahia; government plan; interiorization hotels. Hotel industry: Bahia; hotcls; government plan; tourism interiorization.

\section{INTRODUÇÃO}

A melhor expressão do senso de oportunidade governamental baiano quando, num momento histórico como o início dos anos setenta, decidiu incrementar seu turismo regional, foi a elaboração do I PLANO DE TURISMO DO RECONCAVO - I PTR. Sua posterior implementação, em 1976, com a criação da EMTUR - Empreendimentos Turísticos da Bahia S.A. - e o lapso de tempo entre uma iniciativa e outra, suscitaram vivo interesse pelo estudo. Não só pela forma como esta iniciativa ocorreu, mas também pela análise crítica das ações desse órgão e suas competências.

Na década de setenta, o Governo do Estado, como afirma Santos'

(*) Professor da FACS - Faculdades Salvador e UCSal - Universidade Católica do Salvador. Pós-graduando em Administração do CMAP - [JFBa.

End. para corresp.: Av. Paulo VI. 2114 B. apto. 201 - Itaigara - 41810 - Salvador BA - Brasil. 
dificilmente pessoas detentoras de algum tipo de recurso capaz de provocar cresci. mento econômico, estario dispostas a se envolver em car ter regular com comunidades que nào ofereçam estabelecimentos de hospedagem adequados. Aliado a isto um mesmo volume de capital, se alocado indústria de transfonnaçäo, comércio ou atividade agropecuária, gera, nomnalmente, um número de empregos diretos, signifi. cativamente menor do que se aplicado à áre de hotéis.

O turismo é talvez a maior indústria no que se refere a nível de emprego: em cada 16 trabalhadores, um está empregado no setor, ou seja, em 1989, havia 101 milhōes de empregados em turismo no mundo $^{4}$. Salvador responde a cerca de $90 \%$ do turismo baiano. Isto mostra, com certeza, o baixo desenvolvimento do setor no interior baiano, conseqüentemente, o baixo nível de emprego na área.

A realização das metas projetadas exigiria um processo de interiorizaçāo que reluzisse, em 1995, para cerca de $60 \%$ a polarização em Salvador, e $40 \%$, no ano 2000. Essa projeção exigiria um novo planejamento físico-espacial, a partir de quatro bases estratégicas, centradas em Salvador, que seria a base primária. ${ }^{2}$

A segunda base seria o Recôncavo, que, com suas ilhas e cidades históricas, constitui-se em um desdobramento imediato de Salvador.

A terceira base, que conforma uma área a ser explorada em um turismo rodoviário interno, é um triângulo assim delimitado: no extremo sul da Bahia, regiāo de Cabrália-Porto Seguro; na Chapada Diamantina, onde já se vive todo um desenvolvimento turístico autônomo, centrado em Lençóis; e o próprio Nordeste, a ser dinamizado pelo portão de entrada baiano.*

O estabelecimento dessa estratégia, utilizando as bases, teve como fundamento a falta de recursos financeiros para atendimento a todas as necessidades hoteleiras do interior do Estado. Seria a maneira mais racional de optar por uma localidade, e a menos dependente de interesses pessoais. O objetivo estabelecido pelo Estado para implemen tação das bases foi o de estimular a demanda turística para os serviços de alojamento em cada base.

Além disso, o Plano propunha, ainda, o esforço conjunto entre setores, público e privado, isto porque:

o empresário, muite mais que o (ionemo, tem o sentido do custo operacional, facilidade de administraçáo sobretudo, quando ele é o responsável pela

\footnotetext{
*) Devem ser lembrados dois tópicos: a necessidade de tratamento do Rio Säo Fran cisco, em uma adequadia pers ectiva turística. face à sua grande capacidade de integração regional: e a questão da liheração do jogo no País que. inevitavelmente, de verá ser enfrentada.
}

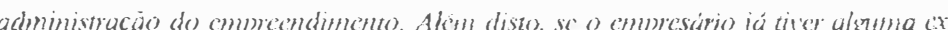
periçncia no ramo hoteleiro, sua combibuç̧ào na elaboraçào do projeto e, cons mę̧ào do emprecendimento, será indispensúvel.

As condiçóes dessa dupla participaçāo atribuíam, ao Estado, a responsabilidarde de construçāo dos hotéis e, à iniciativa privada, explorar (o equipamento por um perí(odo de quatro anos. Por outro lado, caberia à EMTUR a fiscalizaçāo do emprecendimento e a decisāo de renovar o arrendamento, findo o período estabelecido. Entretanto, esse órgão nāo dispunha, até 1989, de nenhum departament() com esta atribuição, cmbora cm maio de 1988, uma comissāo da EMTUR tenha elaborado um parecer técnico, visando definir um programa de privatização dos hotéis do órgão:

precisamos aratiar a decisäo política de privatizaçào des liquipamentos Tiursticos

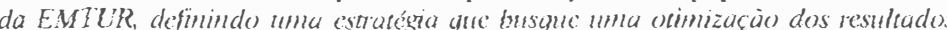
nos aspectos políticos. economicos e sociais. Enendemos que o processo dera ser conduzido com o máximo de critério, analisando todas as situaçèes que se apresentam, risando alcançar o methor resuthado para o kstado... Dois aspectos principais consideramos da mais alta relerência para o encaminhameno do processes: o pri

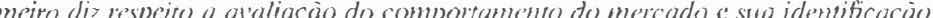
A ari bens cepostos à renda, e a indefiniçáo da políica cconómica do goremo inibe os investidores. que se posicionum em expectatira, pagando de preferencia scus recursos de investimentos de curtíssimo prazo.

A variação do mercado gera, portant(), a necessidade de diferentes tipos de estabelecimentos hoteleiros, como: de lazer, comercial, de apoio a rodovias, "camping", albergues para a juventude etc. Para atendimentu a tal demanda, a EMTUR, a partir de 1979, construiu 16 hotéis com características e situaçōes diversas, alguns dos quais são comentados no item a seguir.

\section{2 "Caminhos da Bahia": Promoção x Planejamento}

\subsubsection{Uma campanta ousada}

Para dinamizar () Plano de Interiorização, a Bahiatursa criou o programa Caminhes da Bahia, tipicamente promocional, utilizando grandes "jogadas mereadológicas" junto às agcencias de viagens, a fim de criar um fluxo turístico regular para o interior:

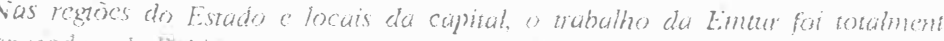

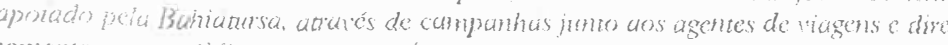
camente comm " plibfico consumidor. 
muda seu padräo de inten'ençào assumindo noras características. Ao invés de fazer políticas compartimentadas - ora agrícola, ora industrial - como ocorreu nas décadas anteriores, procura desenvolvế-las simultaneamentc. Em segundo lugar, essas políticas inten'encionistas, principalmente as vinculadas ao sctor agricola, vào estar subordinadas às diretrizes formuladas pelo governo federal.

A característica central dessa época foi a modernização, procurando criar uma estrutura administrativa descentralizada. Foram criadas várias empresas estatais*, de diferentes setores, além da implantação do Centro Industrial de Aratu (1970) e do Pólo Petroquímico de Camaçari (1976). Embora a inexistência de memória significativa na área turística tenha resultado em relativa pobreza nos depoimentos colhidos, o auxílio da bibliografia permitiu a formulação de algumas questōes.

$\mathrm{O}$ interesse estatal na implementação do turismo regional da $\mathrm{Ba}$ hia, utilizando como chamariz o destaque do papel desse Estado na história do País, a riqueza e força da dominância cultural da etnia africana e, mais recentemente, a relativa importância de sua produção e comércio provocaram, em 1970, a elaboração do I Plano de Turismo do Recôncavo - I PTR. Entre outros objetivos, esse plano visava a ampliação do parque hoteleiro e a exploração de suas praias e ilhas do Recôncavo "sem degradação". Bela peça de planejamento, como comenta Suare $z^{2}$;

realizada num momento extrcmamente oportumo, que cra o auge do milagre econó mico brasileiro. Isto, cntretanto, näo foi suficicnte para o scu sucesso ... O fluxo turistico concentral'a-se, basicamente, em Salvador, onde a iniciativa privada incumbia. se de implantar modema e eficiente rede hoteleira e a infra-estrutura de equipamen. tos e sen iços.

Segundo Martins ${ }^{3}$, essa demanda aponta para vários tipos de mercado:

a) turismo de lazer: passeio, descanso, esporte, diversos em aventura

(*) Cia de Engenharia Rural da Bahia-CERB(1971): Central de Abastecimento da Ba hia S.A.. Ceasa/33a(1969): Companhia Baiana de Eletrificação Rura!, Cober (1972), Companhia Baiana de Pesquisa Mineral. CBPM(1972): Empresa de Assistência Técnica e Extensão Rural da Bahia. Emater-Ba (1974): Nordeste Linhas Aéreas S.A. (1975): Empresa de Pesquisa Agropecuária da Bahia. EPADA (1975): Compr nhia de Desenvolvimento do Vale do Paraguassú - CPVP (1976). hoje Desenvale Bahia Alcool (1980): e Sulba. Companhia Sulbaniano. b) turismo de cultura: procura de conhecimentos através de visitas a sítios históricos, acidentes geográficos, patrimônios culturais e naturais etc;

c) turismo profissional:

econômicas de interesse do consumidor - "tour" de pedras preciosas, "tour" de orquídeas, "tour" de gado, "tour" de petroquímica etc;

d) viagem de negócio: em função de atividades econômicas ligadas à indústria, comércio, agropecuária, mineração, governo, etc.

A variação do tipo de demanda determina, em parte, o tempo de permanência do cliente, além do período do ano em que a taxa de ocupação dos hotéis será mais elevada.

Era necessário, então, que o Estado abrisse novos espaços turísticos, em regiōes mais ricas em atrativos do interior baiano que atendessem aos vários tipos de demanda, e onde a iniciativa privada não se arriscava a investir*. Através da construção de equipamentos de hospedagem e lazer, poder-se-ia aumentar a permanência média do visitante, e reduzir a sazonalidade do fluxo turístico.

\section{PLANO DE INTERIORAÇÃO DO TURISMO}

\subsection{Criação da EMTUR e sua atuação}

A EMTUR - Empreendimentos Turísticos da Bahia S.A., foi instituída em 20 de outubro de 1976, como subsidiária da Bahiatusa, com a finalidade de construir, converter e recuperar meios de hospedagem no interior do Estado. Surgiu, portanto, com a missão de criar essa in fra-estrutura receptiva e assumir a responsabilidade do seu pioneiris mo.

Estabelecia-se, assim, por parte do Estado, uma política de Intevisıtantes na Bahia. Mas, para Martins ${ }^{3}$.

(*) Essa posiçăo de não-investimento é comum no Brasil. Normalmente o empresário aguarda $\bullet$ teste do investimento governamental para depois assumí-lo o pioneirismo da iniciativa pertence. geralmente, do Estado. 
A campanha "Caminhos da Bahia" foi o primeiro grande passo para a integração do interior ao espaço turístico da Bahia. Como principal resultado obteve-se a consolidação de excursōes regulares para dez cidades: Porto Seguro, Ilhéus, Valença, Cachoeira, Paulo Afonso, Jacobina, Juazeiro, Lençóis, Ibotirama e Caldas do Jorro, dentro dos pacotes turísticos oferecidos ao público pelos agentes de viagens.

Além de criar novas destinaçóes turísticas na Bahia, a campanha estimulou o turismo interno, na medida em que despertou o interesse da comunidade para o potencial turístico de sua terra. E, através do direcionamento do crescente fluxo de visitantes para essas regiōes, estimulou o desenvolvimento de uma segura estrutura de serviços turísticos, tornando o setor uma importante atividade econômica em diversas cidades do interior.

\subsubsection{Alguns Resultados}

A atividade turística é um amplo e complexo sistema, onde muitas áreas são importantes ao seu desenvolvimento. Sobre isto Beni diz que:

o turismo é uma atividade que resutta do somatório de recursos naturais do meio ambiente, culturais, sociais econônicos e, assim, o campo de seu estudo é abrangente, complexo c multicausal.

Sob esse enfoque, observa-se que o desenvolvimento do turismo, em uma determinada localidade, exige equipamento e integraçâo de várias forças locais para que se possa atender às motivaçōes do turista. Torna-se imprescindível, por exemplo, um composto de infra-estrutura, urbanização e segurança física.

Quando os equipamentos turísticos estâo sob a administração do Estado, muitas vezes a instabilidade na alocação de recursos e no apoio político provocam descontinuidade no trabalho e, com a diminuição da demanda turística, prejuízo para toda a comunidade. Este foi o caso da Pousada do Convento do Carmo, em Cachoeira, administrado diretamente pela EMTUR. Pelo decreto $n^{\circ} 2392$ de (12/05/89, todos os servidores do Estado em exercício há menos de cinco anos deveriam ser demitidos. Como 25 dos 33 empregados da Pousada eram servidores públicos, seu funcionamento seria inviabilizado caso o decreto fosse cumprido.

Para uma análise mais detalhada do plano de ação da EMTUR, a Tabela a seguir apresenta dados sobre a taxa de ocupação de nove meios de hospedagem incluídos nesse plano.
Tabela - Taxa de ocupação dos meios de hospedagem classificados. Caminhos da Bahia. 1986-89

\begin{tabular}{lllll}
\hline Discriminação & $\mathbf{1 9 8 6}$ & $\mathbf{1 9 8 7}$ & $\mathbf{1 9 8 8}$ & $\mathbf{1 9 8 9}$ \\
\hline $\begin{array}{l}\text { Hotel Velho Chico } \\
\text { (Ibotirama) }\end{array}$ & 60.0 & 50.2 & 46.4 & 40.2 \\
$\begin{array}{l}\text { Pousada de Lençóis } \\
\text { (Lençóis) }\end{array}$ & 25.8 & 26.0 & 29.1 & 39.0 \\
$\begin{array}{l}\text { Hotel Rio Una } \\
\text { (Valença) }\end{array}$ & 35.9 & 38.0 & 15.5 & 24.3 \\
$\begin{array}{l}\text { Hotel Serra do Ouro } \\
\text { (Jacobina) }\end{array}$ & 57.9 & 44.1 & 39.1 & 37.6 \\
$\begin{array}{l}\text { Grande Hotel Caldas de Cipó } \\
\text { (Cipó) }\end{array}$ & 31.3 & 21.4 & 14.8 & 12.7 \\
$\begin{array}{l}\text { Convento do Carmo } \\
\text { (Cachoeira) }\end{array}$ & 54.1 & 36.1 & 30.7 & 26.0 \\
$\begin{array}{l}\text { Pousada do Guerreiro } \\
\text { (Cachoeira) }\end{array}$ & 53.1 & 15.4 & 26.6 & -3 \\
$\begin{array}{l}\text { Grande Hotel de Itaparica } \\
\text { (Itaparica) }\end{array}$ & 24.4 & 25.4 & 16.6 & 16.9 \\
$\begin{array}{l}\text { Hotel de Juazeiro } \\
\text { (Juazeiro) }\end{array}$ & 61.9 & 57.3 & 41.4 & 38.5 \\
\hline
\end{tabular}

Fonte: Boletim de Ocupaçâo Hoteleira - BOH (Bahiatursa)

(a) No ano de 1989 năo foram fornecidos os dados do mês de dezembro do Hotel Rio Una; novembro e dezemlro da Pousada do Convento de Cachoeira; e o ano todo da Pousada do Guerreiro.

Esclarece-se que a maior taxa de ocupação apresentada pelo Hotel Velho Chico (Ibotirama) justifica-se por ser um hotel de turismo rodoviário entre Salvador e Brasília.

Graças a uma boa taxa de ocupação, em 1989, foram privatizados os hotéis de Lençóis e Valença. O primeiro foi adquirido pela Adventur (Agência de viagens) e o segundo por um empresário baiano, proprietário também de uma agência de viagens. Isto facilita bastante a promoção do equipamento pela facilidade de apelos mercadológicos que ambos possuem. Por outro lado, ambos têm localização privile giada, pois ficam em regiōes de grande demanda turística. Lençóis que já abrigou até o Consulado Francês na época do Ciclo da Mineração, localiza-se fm uma regiāo serrana, cheia de grutas e cachociras, sendo bastante procurada por proporcionar turismo ecológico. A demanda por Valença justifica-se pela sua proximidade do Morro de São Paulo.

O Hotel de Itaparica, também privatizado, já não mantém a mesma taxa de ocupaçäo dos outros, sobretudo no inverno. Isto deve-se. 
principalmente, à falta de promoção e, também, face à sua localização que depende do "ferry-boat", freqüentemente congestionado. Apesar de pertencer à iniciativa privada desde 1976, sua taxa de ocupação vem decrescendo a cada ano.

Outros hotéis não incluídos nessa tabela, por falta de dados oficiais da Bahiatursa, como o de Euclides da Cunha (Hotel dos Conselheiros) e o de Cícero Dantas (Hotel Serra do Boqueirão), apresentam taxas de ocupação baixíssimas. Por essa razão, a sua privatização é difícil de ser concretizada.

A idéia inicial da Emtur era de implantar o hotel e, na época em que o local já dispusesse de uma infra estrutura turística adequada privatizá-lo. Com isso percebe-se que a infra-estrutura necessária e os requisitos para a criação dos hotéis, não foi muito bem analisada, ou, então, sofreram grande pressão política ou econômica. Neste último caso, estaria incluído o requintado Hotel de Piritiba que foi arrendado, inicialmente, em 1986. Piritiba é um município muito pouco conhecido pelos baianos, e com poucos atrativos. No entanto, "critérios políticos" prevaleceram sobre os pré-fixados pela EMTUR.

Já o Hotel do Prado foi o primeiro a ser privatizado em janeiro de 1987, alguns meses após sua inauguração. Percebendo o valor e a atração que a cidade poderia exercer sobre os turistas, o hotel, com excelente equipamento, foi adquirido pela SOLETUR (Agência de Turismo). Hoje é parada obrigatória para toda excursão dessa agência que vem do Sul do País.

Há outros hotéis que, apesar de estarem arrendados e exigirem fiscalização da EMTUR, vivem em quase completo abandono, tornando difícil a criação de uma demanda turística naquelas localidades. Tem-se, como exemplo, o Hotel Acaraí (Camamu) e o Hotel Caldas de Cipó (Cipó). Nesses, nem mesmo as condiçōes de higiene e limpeza são observadas. Pelos dados da Tabela, nota-se a decadência na taxa de ocupação do Hotel de Cipó, que já foi um excelente balneário: em três anos a taxa decresceu em quase $50 \%$.

Em 1989, foram implantados mais dois hotéis: O Rio das Pedras (Campo Formoso) e o Jequiriçá, em cidade do mesmo nome que, pela ausência de divulgação ou campanhas promocionais, apresentam baixa taxa de ocupação. Tendem portanto a ser depreciados e ter dificultada sua aquisição pela iniciativa privada.

\section{TEORIA X PRÁTICA NA PILANIFICAÇão REGIONAL DO TURISMO}

No que se refere à planificação regional do turismo, Acerenza ${ }^{8}$ afirma que, na América, esta se iniciou com o Plano de Desenvolvimento Regional para Cuzco e Puno, no Peru. De fato em 1969, o governo desse país seguiu as recomendaçōes da missão enviada pelo Programa das Naçōes Unidas para o Desenvolvimento (PNUD) e criou uma comissão especial para coordenar e supervisionar o Plano Turístico e Cultural PERU/UNESCO, conhecido pelo nome de Projeto COPESCO.

Anos mais tarde, o Brasil iniciou estudos para o desenvolvimento turístico do extenso litoral compreendido entre a cidade do Rio de Janeiro e o porto de Santos. Entre 1972 e 1973, realizaram-se trabalhos denominados Projetos TURIS dos quais participou a empresa de consultoria SCET Internacional, cuja equipe técnica havia trabalhado no Projeto LANGUEDOC-ROUSILLON, com uma contrapartida nacional, formada por especialistas brasileiros.

Segundo Acerenza ${ }^{8}$, no curto período no qual se desenvolve o processo formal de planejamento do turismo por parte do Estado, é possível observar que o mesmo tem obedecido a distintas orientaçōes, respondendo a necessidades de ordem física e econômica. Para ele há três enfoques, a serem considerados, como descrito a seguir:

a) Enfoque Urbanístico

Prevaleceu na Europa na década de 60. Fundamenta-se em uma análise e avaliação detalhada dos recursos turísticos, geralmente de ordem física, com base na qualidade e possibilidades de exploração dos mesmos. Tal orientação é comprovada na Bahia, quando se observa que em todos os projetos de implantação de equipamentos turísticos do interior, há uma preocupação em torno dos recursos naturais de cada localidade.

b) Enfoque de Política Econômica

Teve seu início na década de 60 . Essa nova orientação contribuiu para impulsionar ainda mais o novo enfoque no estabelecimento,

cialmente o Banco Mundial e o Banco Interamericano de Desenvolvimento, além da abertura de novas linhas de crédito destinadas ao fomento do turismo, o que constituiu um grande estímulo para o empreendimento de planos destinados ao desenvolvimento do setor.

Logicamente, a América nào escapou à influência da nova orientaçào que começou a manifestar-se já nos primeiros anos da década de 70, ainda que na realidade tenha se dado com maior ímpeto em 1974, por ocasiào do Primeiro Seminário sobre Planejamento de Desenvolvimento Turístico do qual participaram, pela primeira vez, ...especilistas das empresas de plancjamento de vários países do continente. 
c) Enfoque PASOLP

Nos últimos anos, como conseqüência da orientação parcial que caracterizou o planejamento do turismo, e do desejo de abordar seu desenvolvimento de forma integral, começaram a desenvolver-se novos enfoques. Entre os modelos concebidos com este fim, destaca-se o enfoque PASOLP - "Products Analysis Sequence for Out Leisure Planning" (Seqüência da Análise de Produto para o Planejamento do Tempo Livre). O modelo PASOLP é um novo enfoque sobre o planejamento do turismo e atividades recreativas, desenvolvido entre 1976 e 1977 por M.Band - Borry e baseia-se no conceito de produto turístico, sobre o qual, precisamente, guia todo o processo.

Utilizando como referência os enfoques citados, constata-se que o turismo na Bahia adota ainda apenas o enfoque urbanístico, e ensaia o de política econômica.

\section{CONSIDERAÇÖES FINAIS}

Como comenta ACERENZA ${ }^{8}$ o planejamento é um processo que exige grande cuidado em seu exercício, já que as conseqüências de um planejamento errado e incompleto afetam, não só o próprio trabalho, mas também a economia e, portanto, o bem estar das pessoas, inclusive a prosperidade da empresa ou da atividade tratada, se este processo é oficial. Suas principais etapas deveriam ser: identificação do problema e definição dos objetivos; análise e avaliação da situação; formulação das ações; programação das ações; aprovação e caracterização para levar a termo o plano; execução do plano.

Faltou ao projeto da EMTUR adequada elaboração e uma racional gradação na etapas do plano. Falharam, ainda, as análises econômico-financeiras que fundamentaram a viabilidade da implantação de alguns desses equipamentos; ou, então, prevaleceram critérios de clientelismo político sobre os estudos. Fez-se presente mais uma vez a descontinuidade da ação estatal:

O atual marco institucional do aparato público voltado para o planejamento e fo mento do turismo na Bahia, refiete de forma direta o baixo desenvol timento do secor. Como se sabe, o turismo ainda neo tem, no Estado, um status sequer de Secreta. ri de Goremo. A Bahiatursa, maior empresa do sistema estatal de turismo, encontra-se hierarquicamente subordinada à Secretaria de Indústria Comércio e Turismo que, apesar do nome, näo tem nenhuma estrutura intema voltada diretamente para o setor
Numa perspectiva já ultrapassada, o turismo na Bahia tem sido tratado como um negócio individual quase que resumido à hotelaria sem nenhuma ligação direta com os setores vinculados à cultura, ao lazer c ao desenvolvimento urbano/ambiental.

O que acontece na realidade, é que o turismo ainda não é visto como uma atividade rentável para os Estados e Municípios. Desta forma, não há empenho tanto dos políticos profissionais, quanto dos admin

Muitas vezes, o desenvolvimento turístico dá-se pelo senso de oportunidade da iniciativa privada. Por exemplo, antes da iniciativa de construção de um hotel cinco estrelas na ilha de Comandatuba, no litoral baiano, pela rede de hotéis TRANSAMERICA, a administração do município de UNA jamais promoveu aquela região. Percebe-se, pois, a existência de enormes "vazios turísticos" não enfocados política e financeiramente pelo Governo Estadual Baiano.

Quanto à adoção do enfoque PASOLP, depende da climinação de um preconceito arraigado no planejamento brasileiro: programar o la zer. Encarado como supérfluo, pois não representa fonte de renda di reta para o Estado, acaba por depender da imaginação e criatividade da própria população.

Potencialmente de grande importância para o desenvolvimento do turismo no interior baiano, a EMTUR precisava ter assegurado a privatização dos hotéis, findo o prazo de arrendamento, pelas seguintes razōes:

a) dificuldade de controle e fiscalização dos hotéis;

b) desgaste da freqüente descontinuidade das políticas públicas;

c) baixa ocupação dos hotéis e sua conseqüente desvalorização.

A privatização deveria ocorrer assim que o hotel pagasse o seu in vestimento. Porém, pela falta de uma visão empresarial e mercadológica, além da interferência do clientelismo político no setor público, acabou sendo fcita com prejuízo para a EMTLR. Tais dificuldades acabaram provocando a incorporação da CONBAHIA e EMTUR pela BAHIATURSA que tornou-se a única empresa do Sistema Estadual de Turismo.

Uma tentativa de mudança desse quadro poderia ocorrer desvinculando-se a BAHIATURSA da Secretaria de Indústria e Comércio, conferindo àquela status de Secretaria de Estado. L'ma de suas ações poderia ser a criação de um Hotel-Escola, com o objetivo de qualificar pessoal para trahalhar em hotéis do intcrior haiano. 
Aliada à implantação de hotéis, o crescimento do turismo no inte. rior baiano depende da fixação de critérios rígidos, apoiados, por exemplo, na localização, nos recursos naturais e culturais dos municípios, que determinem as decisões a serem tomadas.

A criação de um novo programa em termos promocionais, a exemplo do Caminhos da Bahia poderia constitui

desenvolvimento organizado do Turismo no Interior da Bahı, alem de servir de modelo para outros Estados do País.

\section{REFERÊNCIAS BIBLIOGRÁFICAS}

1. SANTOS, Reginaldo Souza. Notas preliminares sobre o padrāo de intervençào do Es. tado da Bahia (1955-80). Revista de Administração Pública. Rio de Janeiro 22(2): $52-74$, abr/jun, 1988.

2. SUAREZ, Marcus Alban. Salvador: uma alternativa pós-industrial. Salvador, 1990.

3. MARTINS, Dionizio. Ajustes para a formulaçào de um processo de política de ação dø Governo do Estado da Bahia. 1985.

4. EMBRATUR. Os números do turismo. Porto Alegre, 1990.

5. EMTUR. Parecer técnico. Salvador, 1988. (documento de trabalho).

6. BAHIATURSA. Relatório (1979-1989). Salvador. Bahiatursa.

7. BENI, Mario Carlos. Sistema de Turismo-SISTUR: estudo do turismo face a moder na teoria de sistema. Turismo cm análise. São Paulo, v.1, n.1, p.15-34, mai. 1990.

8. ACERENZA, Miguel Angelo. Administracion del turismo: planificacion y direcion Mexico, Trillas, 222p. 1985. 